\title{
Non-Radiative Losses in Metal Halide Perovskites
}

\author{
Samuel D. Stranks*
}

Cavendish Laboratory, JJ Thomson Avenue, Cambridge CB3 0HE, United Kingdom

ORCID: 0000-0002-8303-7292

\section{Corresponding Author}

*sds65@cam.ac.uk

\begin{abstract}
Metal halide perovskites are generating enormous interest for their use in solar cells and lightemission applications. One property linking the high performance of these devices is a high radiative efficiency of the materials; indeed, a prerequisite for these devices to reach their theoretical efficiency limits is the elimination of all non-radiative decay. Despite remarkable progress, there exists substantial parasitic non-radiative recombination in thin films of the materials and when interfaced into devices, and the origin of these processes is still poorly understood. In this perspective, I will highlight key observations of these parasitic pathways on both the macro- and micro-scale in thin films and full devices. I will summarize our current understanding of the origin of non-radiative decay, as well as existing solutions that hint at facile ways to remove these processes. I will also show how these non-radiative decay pathways are intimately related to ionic migration, leading to the tantalizing conclusion that eliminating one phenomenon could in turn remove the other, ultimately pushing devices to their theoretical limits.
\end{abstract}




\section{Biography}

Samuel D. Stranks is a Royal Society University Research Fellow and Group Leader in the

Cavendish Laboratory at the University of Cambridge. He completed his $\mathrm{PhD}$ at the University of Oxford, investigating carbon nanotubes for organic solar cell applications. He then turned his focus to the optoelectronic properties of perovskites as a Junior Research Fellow at Oxford and then as a Marie Curie Fellow at MIT. He was awarded the 2016 IUPAP Young Scientist in Semiconductor Physics Prize for his contributions to the field of perovskite optoelectronics.

\section{TOC GRAPHICS}

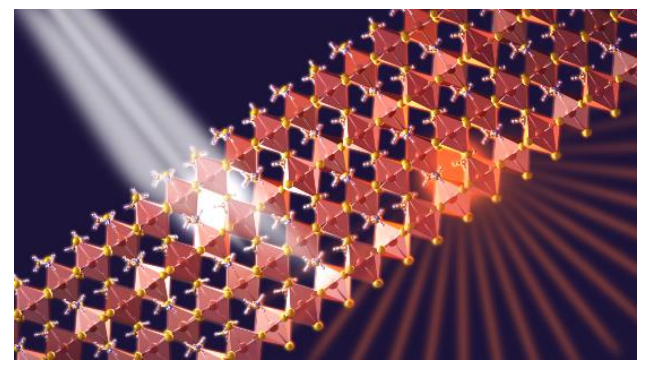

Metal halide perovskites are crystallized from organic and/or inorganic salts into the $\mathrm{ABX}_{3}$ structure, where $\mathrm{A}$ is a cation (methylammonium, MA; formamidinium, FA; cesium, Cs, or mixtures $^{1}$ ), $\mathrm{B}$ a metal cation (typically $\mathrm{Pb}$ ), and $\mathrm{X}$ a halide $(\mathrm{Cl}, \mathrm{Br}$, I, or mixtures). Perovskites offer simple bandgap tunability by changing the composition ${ }^{2}$ and low-temperature processability. These materials defy conventional wisdom in that they have moderate defect densities yet retain excellent optoelectronic properties including sharp absorption edges ${ }^{3}$ and long charge carrier diffusion lengths ${ }^{4}$. Over the last 7 years, we have witnessed a meteoric rise in the power conversion efficiency (PCE) of perovskite solar cells from $3.5 \%$ to $22 \%{ }^{5,6}$, which is now comparable to record efficiencies of commercial thin-film PV technologies but still lower than record crystalline silicon (c-Si) devices. While PV cells convert light into electrical power, light-emitting diodes (LEDs) 
operate in the reverse by transforming electricity into emitted light through electroluminescence (EL). Recent reports of emissive and colour-tunable perovskite bulk films ${ }^{7}$, nanocrystals ${ }^{8-10}$ and nanoplatelets ${ }^{11}$ are particularly promising for LEDs ${ }^{12}$, with external quantum efficiencies (EQEs) of NIR LEDs now reaching $\sim 12 \%{ }^{7,13,14}$.

Despite rapid progress, perovskites are still far from their full potential. The emission quantum efficiencies in state-of-the-art materials are far from unity under solar conditions ${ }^{15,16}$, particularly in wide-bandgap mixed-halide perovskites ${ }^{17,}{ }^{18}$. This suggests that defects are still not entirely benign. Devices also show poor luminescence indicating that there is further non-radiative recombination at the contacts ${ }^{19}$. Any non-radiative recombination impairs charge density build-up and limits open-circuit voltage. Thus, an essential condition for PV and LED devices to reach their efficiency limits is the elimination of all non-radiative recombination ${ }^{20}$.

In this perspective, I will summarize the key observations of non-radiative losses in perovskite materials and devices such as solar cells and light-emitting diodes, and review our current understanding of the origins of these parasitic recombination pathways. I will highlight some of the reported methods to reduce the fraction of non-radiative recombination in these materials, methods which are as yet imperfect but hint at routes towards defect-free bulk and surfaces. I will also propose the connection between non-radiative decay and transient phenomena in these materials such as ionic migration, suggesting tantalizing common solutions to both. A thorough understanding of the origin of these phenomena will alone lead to rational solutions to their elimination, and ultimately yield device performances approaching theoretical limits.

An excellent solar cell should also be an excellent LED ${ }^{21}$. This seemingly counterintuitive concept can be understood by considering recombination of charge carriers at open-circuit in a solar cell. To build up a large open-circuit voltage, we need to maintain a high photo-excited charge carrier 
density. Photo-excited electrons and holes in an ideal semiconductor will eventually recombine (radiatively) by emitting a photon. However, any non-radiative recombination will result in additional parasitic recombination pathways of carriers to lower-energy states, leading to lower quasi-Fermi levels and effective charge densities and, ultimately, lower open-circuit voltages. A good analogy for voltage losses from non-radiative decay is a 'leaky' dam, where parasitic leak (loss) pathways will impair our ability to maintain the water level (voltage) at its highest possible level.

However, it is not only the internal luminescence efficiency that must be optimized. The maximum thermodynamic potential difference between the ground and excited states of any photochemical system is when photon absorption and emission are balanced ${ }^{22}$. In order to incur minimal losses, the external luminescence from a solar cell device must be equal and opposite in rate, direction and solid angle to incoming sunlight from a point source. Due to the narrow escape cone for light from a device, particularly for materials which have a moderate refractive index (including GaAs and perovskites ${ }^{23}$ ), efficient external luminescence requires repeated escape attempts through multiple absorption and re-emission photon recycling events ${ }^{24}$ and an internal luminescence efficiency approaching $100 \%^{20,25}$.

The reciprocity relationship, first proposed by $\mathrm{Rau}^{21}$, allows the measured device $V_{\mathrm{OC}}$ to be formulated in terms of a non-radiative voltage loss $\Delta V_{\mathrm{OC}}^{\text {non-rad }}$ from the maximum achievable voltage after unavoidable thermodynamic losses $V_{\mathrm{OC}}^{\max }$ by:

$$
V_{\mathrm{OC}}=V_{\mathrm{OC}}^{\mathrm{max}}-\Delta V_{\mathrm{OC}}^{\mathrm{non}-\mathrm{rad}}=V_{\mathrm{OC}}^{\max }-\frac{k T}{q}\left|\ln \left[\eta_{\mathrm{LED}}\right]\right|
$$

where $k$ is the Boltzmann constant, $T$ the temperature, $q$ the charge of an electron and $\eta_{\text {LED }}$ the external quantum efficiency of the device operating as an LED. It is noted here that $\eta_{\text {LED }}$ is closely related to the external radiative efficiency (ERE) of a device ${ }^{26,27}$. This relation allows the open- 
circuit voltage to be derived from the luminescent properties of the same device. Analogous relations allow the short-circuit current to be determined from the electroluminescent emission. Thus the key PV parameters can be derived from the electroluminescent properties of the device. The measured open-circuit voltages of a variety of PV technologies are shown in Figure 1, along with the components of non-radiative loss (red) from the thermodynamic limits obtained from the Shockley-Quiesser limits. These non-radiative losses arise from, among others, defects (charge carrier traps) in the bulk materials, additional recombination pathways or defects when the material is interfaced with device contacts, poor external light out-coupling, many-body effects such as Auger processes, and, in the case of silicon, recombination via an indirect bandgap. The most efficient single junction PV devices to date are made from GaAs (power conversion efficiency of $28.8 \%$ ), which has been shown to have internal luminescence quantum efficiencies $>99 \%^{28}$, with external radiative efficiency of $32.3 \%{ }^{27}$ and less than $\sim 40 \mathrm{mV}$ of non-radiative $\operatorname{loss}^{29}$. On the other extreme, organic photovoltaics (OPV) have poor external radiative efficiencies $\left(\sim 10^{-5} \%\right)$ owing in part to high defect densities and losses at exciton dissociation heterojunctions, and thus suffer from substantial non-radiative losses $(\sim 400 \mathrm{mV})^{29}$. A clear pathway to improving many of the technologies is by eliminating all non-radiative losses. 


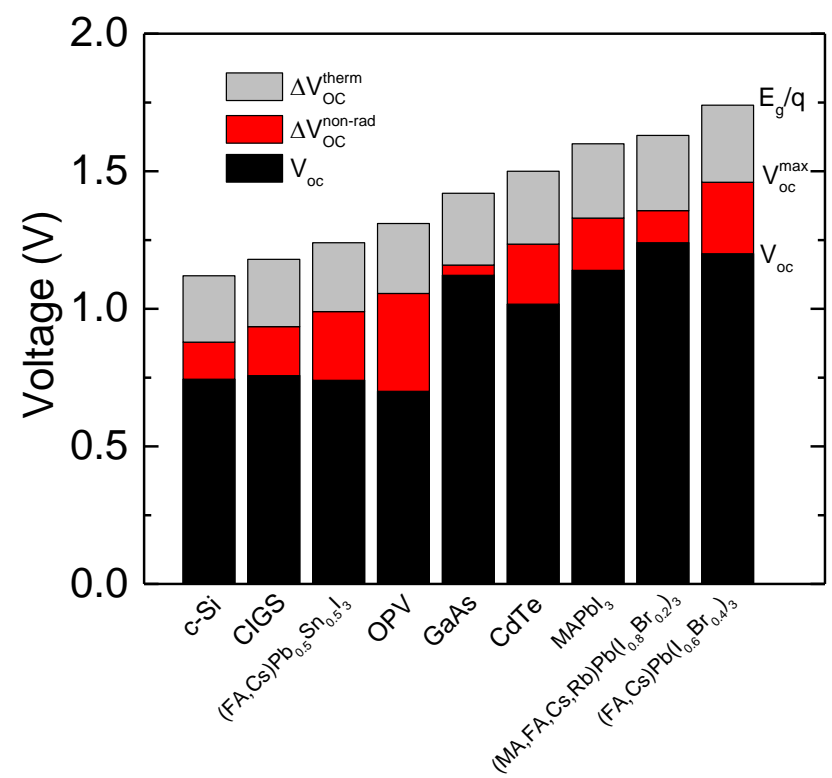

Figure 1. Open-circuit voltages and losses for best-in-class solar cells for a variety of PV technologies. The measured $\mathrm{V}_{\mathrm{oc}}$ is in black, the non-radiative loss from the maximum possible $V_{\mathrm{OC}}^{\max }$ is in red, and the unavoidable thermodynamic loss from the bandgap $\left(\mathrm{E}_{\mathrm{g}}\right)$ is in gray. Measured $\mathrm{V}_{\mathrm{oc}}$ values for c-Si, CIGS and GaAs devices are taken from Green et al. ${ }^{30}$, CdTe from Burst et al. $^{31}$, OPV (PDPP3T:PC 61 BM) from Yang et al. ${ }^{29}$, (FA,Cs)Pb ${ }_{0.5} \mathrm{Sn}_{0.5} \mathrm{I}_{3}$ from Eperon et al. ${ }^{32}$, $\mathrm{MAPbI}_{3}$ from Momblona et al. ${ }^{33}$, (MA,FA, Cs, $\left.\mathrm{Rb}\right) \mathrm{Pb}\left(\mathrm{I}_{0.8} \mathrm{Br}_{0.2}\right)_{3}$ from Saliba et al. ${ }^{34}$, and (FA,Cs) $\mathrm{Pb}\left(\mathrm{I}_{0.6} \mathrm{Br}_{0.4}\right)_{3}$ from McMeekin et $\mathrm{al}^{35}$. The $V_{\mathrm{OC}}^{\mathrm{max}}$ values in the Shockley-Queisser limit were computed from detailed balance calculations based on step-function absorptances with onset at the material bandgap, and the AM1.5 solar spectrum. Note that the non-radiative loss $\Delta V_{\mathrm{OC}}^{\text {non-rad }}$ defined here will also include a component of loss accounting for the deviation of the absorptance profile for a solar cell material from the ideal step-function ${ }^{29}$.

Recent reports of perovskite devices have shown remarkably low voltage losses, which is consistent with reasonable external electroluminescence quantum efficiencies ${ }^{33,36}$. Saliba et al. recently reported devices with quadruple cation perovskites (MA, FA, Cs and Rb), yielding an 
impressive voltage of $1.24 \mathrm{~V}$, which is only $\sim 120 \mathrm{mV}$ shy of the radiative limit ${ }^{34}$. This high voltage is in line with the measured external EL efficiency of $3.8 \%$. However, the logarithmic relationship between voltage and luminescence efficiency from Eq. 1 means that removing even this small final voltage loss will require an increase in the luminescence by at least a factor of $25^{19,34}$. These losses are even more substantial in the wider band gap perovskites achieved with larger fractions of bromide $^{17,18,37}(\sim 260 \mathrm{mV})$. Despite remarkable progress, there is still work to be done to ameliorate all non-radiative losses to push them to their limits.

These losses are particularly evident when considering the PL quantum efficiency (PLQE) of the neat perovskite materials ${ }^{15}, 17$. The external (measured) PLQE $\eta_{\text {meas }}$ of a polycrystalline thin film of $\mathrm{MAPbI}_{3}$ is shown in Figure 2a (black squares). The internal PLQE values $\eta$ (red circles) are calculated using the relationship presented by Richter et al. in which we account for the losses from photon recycling and poor light outcoupling from a perovskite/air and perovskite/glass interface:

$$
\eta=\left[\frac{\eta_{\text {esc }}}{\eta_{\text {meas }}}+\left(1-\eta_{\text {esc }}\right)\right]^{-1}
$$

where $\eta_{\text {esc }}=12.7 \%$ is the escape probability of a photon from a bare $\mathrm{MAPbI}_{3}$ perovskite film on glass for this given film thickness ${ }^{38}$. It is important to note the significant difference between the external and internal values, and care needs to be taken to account for outcoupling differences when comparing the external luminescence measurements of films. The luminescence efficiency increases as the excitation density increases and saturates at high charge density. This trend is generally attributed to a filling of sub-gap trap states with photo-excited carriers ${ }^{16}$, with the excitation-dependent effects reaching a plateau at high excitation densities corresponding to $>10$ sun-equivalent ${ }^{16}$. At intensities equivalent to 1 sun illumination, there are still substantial losses from internal non-radiative decay processes even in the highest quality films. 

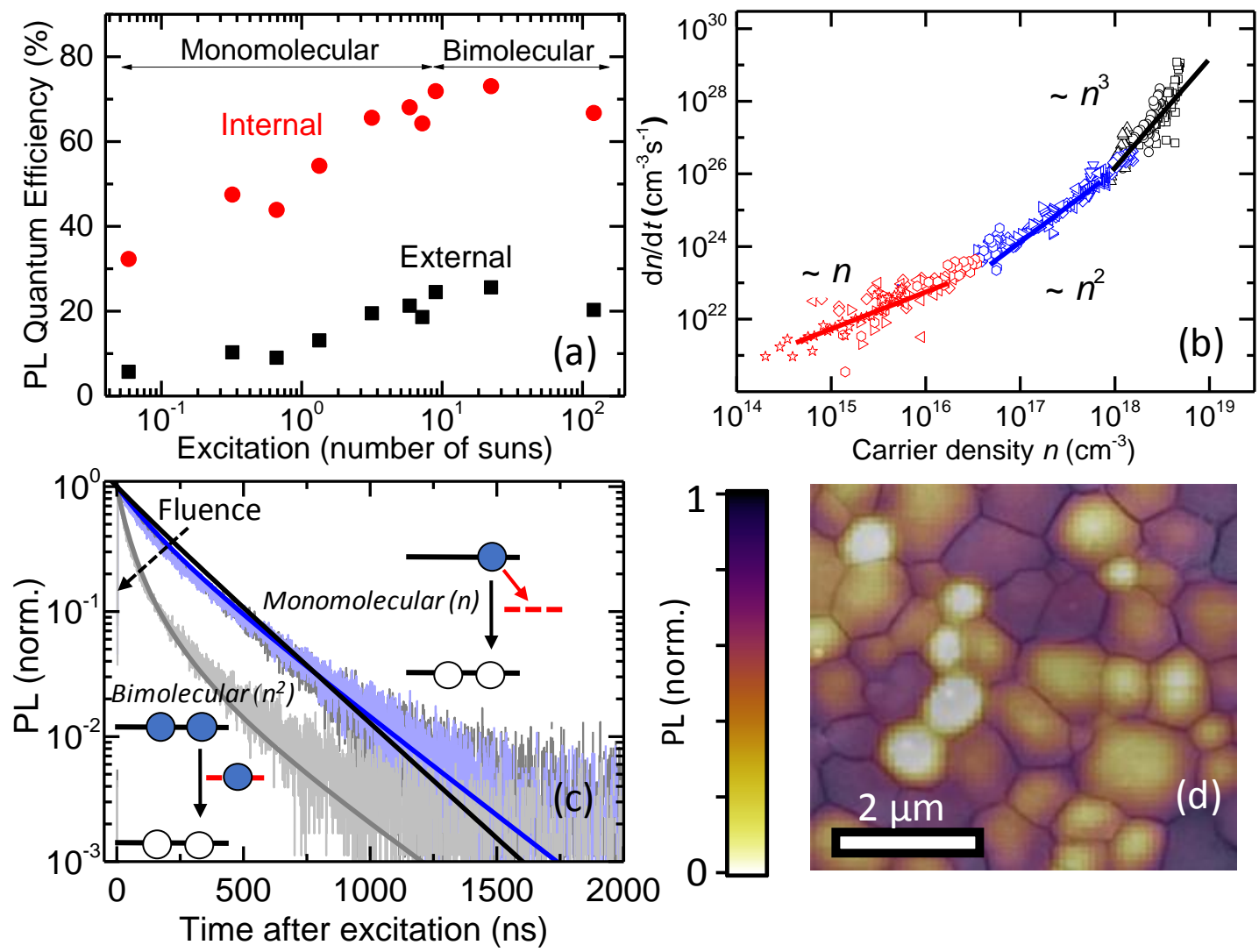

Figure 2. (a) External and internal PL quantum efficiency as a function of excitation power of a thin film of $\mathrm{MAPbI}_{3}$ prepared via a $\mathrm{PbCl}_{2}$ route on glass. The approximate monomolecular (trapassisted) and bimolecular recombination regimes are marked. (b) Recombination rate $\mathrm{d} n / \mathrm{d} t$ as a function of charge density $n$ for $\mathrm{MAPbI}_{3}$ films as extracted from transient absorption measurements. Solid lines are guides to the eye to highlight the different recombination regimes. Reproduced with permission from Nature Publishing Group ${ }^{38}$. (c) Time-resolved PL kinetics for the same thin film of $\mathrm{MAPbI}_{3}$ from a), photo-excited with various pulse fluences. Black, blue and gray are with excitation densities equivalent to $\sim 10^{15}, \sim 10^{16}, \sim 10^{17}$ excitations per $\mathrm{cm}^{3}$, respectively. The schematics represent the dominant recombination regime in each case. Adapted with permission from the American Physical Society ${ }^{16}$. (d) Confocal PL intensity map of a film of $\mathrm{MAPbI}_{3}$ clearly showing emission heterogeneity. Adapted with permission from Nature Publishing Group ${ }^{39}$. 
The various recombination processes of charge carriers can be summarized in a simplified way as:

$$
-\frac{d n}{d t}=k_{1} n+k_{2} n^{2}+k_{3} n^{3}
$$

where $n$ is the charge density, $k_{1}$ is a rate constant representing monomolecular channels such as trap-assisted recombination, $k_{2}$ is the bimolecular band-to-band recombination rate constant and $k_{3}$ is the third-order Auger recombination constant ${ }^{16,38,40}$. These regimes can be seen as a function of charge density $n$ in Figure 2b, which shows the kinetics extracted using transient absorption on thin films of $\mathrm{MAPbI}_{3}{ }^{38}$. In Figure 2c, the time-resolved PL kinetics from a similar film when photoexcited with a pulsed source with different fluences is shown ${ }^{16}$. At low excitation densities in which there are unfilled trap states, the PL kinetics are dominated by pseudo-monomolecular channels governed by the concentration of minority untrapped carriers (electrons) whose population is affected by trap-assisted recombination. At higher fluences when the traps are filled, there are comparable numbers of free electrons and holes, resulting in bimolecular-dominant kinetics. The transition between the monomolecular and bimolecular regimes is an approximation for the trap density ${ }^{16}$, which in the case of the films shown here is $N_{\mathrm{T}} \sim 10^{16} \mathrm{~cm}^{-3}$.

Although the decay of carriers can be governed by a range of processes, it is emphasized that the radiative recombination events are governed by bimolecular recombination of free electrons and holes for both $\mathrm{MAPbI}_{3}$ and $\mathrm{MAPbBr}$, as was shown recently by Richter et al using complementary transient absorption and photoluminescence data ${ }^{38}$. The fact this process involves recombination of free electrons and holes is consistent with the low exciton binding energies $\left(\sim 5-25 \mathrm{meV}^{41,42}\right)$ reported for these three-dimensional perovskites at room temperature. Combining PL measurements (probing radiative pathways) with other time-resolved measurements such as microwave conductivity (probing recombination of mobile carriers) and transient absorption 
(probing recombination pathways of all species with optical signatures) is a powerful approach to elucidate behavior of charges that do not contribute to radiative events such as the recombination of free holes after trapping of electrons ${ }^{15,43}$.

Nevertheless, even in the bimolecular-dominant regime where the luminescence reaches its maximum, the internal PLQE value plateaus at $\sim 70 \%$, suggesting that there is still non-radiative decay. This could be in part due to the onset of competing non-radiative Auger processes. However, Richter et al. recently proposed that the bimolecular rate constant is not purely radiative and in fact has a non-radiative component which is not removed from trap filling. The nature of this non-radiative bimolecular decay pathway is unclear but it will be a topic of future intense interest in the community as it may hold the key to closing the final voltage losses.

The non-radiative losses in $\mathrm{MAPbI}_{3}$ films can be visualized by considering the microscale photoluminescence properties ${ }^{44,}{ }^{45}$, as shown in the photoluminescence map overlaid over a scanning electron microscope (SEM) image in Figure 2d. There is substantial heterogeneity in microscale emission, with a large fraction of 'dark' grains, consistent with a spatial heterogeneity in trap density ${ }^{46}$. These PL intensity heterogeneities are also reflected in PL lifetimes, with the dark grains typically exhibiting fast non-radiative decay components while the brighter grains show much longer lifetimes; these decays converge as the excitation fluence is increased to fill the traps $^{44}$. The spatial heterogeneities have also been observed in excited state relaxation kinetics ${ }^{47}$, trap-related blinking ${ }^{48}$, and charge carrier diffusion length ${ }^{49}$; the latter is a quantity which is intrinsically related to the charge carrier lifetime extracted from PL lifetime measurements ${ }^{4,50}$. Initial time-resolved PL studies suggested that the grain boundaries are also regions of faster nonradiative decay ${ }^{44}$ which affect carrier mobility ${ }^{51}$. However, several recent studies have suggested that grain boundaries are benign for charge carriers ${ }^{52,53}$. This an important ongoing debate, further 
complicated by the fact that grain boundary recombination will likely depend sensitively on a number of factors including sample processing route, grain size, and illumination conditions. Spectroscopic measurements of the films are powerful in revealing the non-radiative decay losses, allowing an optically-implied (internal) open-circuit voltage to be predicted ${ }^{17}$. However, full devices show poor luminescence efficiencies indicating that there is also substantial non-radiative recombination at the $\operatorname{contacts}^{19}$ as well as poor external light coupling, which must also be resolved. Indeed, the microscale spatial heterogeneity is also seen in the photocurrent and opencircuit voltage in solar devices ${ }^{54-57}$. Curiously, Eperon et al found an anticorrelation between grains bright in photoluminescence and those grains efficient in charge collection. This seemingly counterintuitive finding reveals that the performance of even the state-of-the-art solar cells is still limited by losses at the contacts. In the ideal cell at short-circuit, the luminescence should be substantially quenched but at open-circuit the PL quantum efficiency should be maximised with an external PLQE approaching $100 \%{ }^{20}$. The recent results by Saliba et al. showing high external luminescence quantum efficiencies suggests that the interfaces in the multiple cation systems are superior and the final gains might be achieved by further optimizing the perovskite material itself. The precise nature of the traps in the neat materials is still unclear ${ }^{58}$. There is mounting evidence to suggest that it is the electron that is trapped ${ }^{59,60}$, though additional hole traps cannot be ruled out. We can extract approximate trap densities leading to the pseudo-monomolecular decay component using the kinetic trap model (Fig. 2 c), with calculated densities typically $\sim 10^{15}-10^{16}$ $\mathrm{cm}^{-3}$ in polycrystalline thin films, corresponding to around one in a million unit cells containing a defect $^{16,43,61}$. The trap densities are comparable to high quality organic materials ${ }^{62}$ but higher than other PV thin film technologies such as copper indium gallium selenide (CIGS) $\left(\sim 10^{13} \mathrm{~cm}^{-3}\right)^{63}$, and much higher than perovskite single crystal embodiments $\left(\sim 10^{9}-10^{12} \mathrm{~cm}^{-3}\right)^{64,65}$ and other highly 
crystalline semiconductors such as $\mathrm{c}-\mathrm{Si}$ (as low as $\left.10^{8} \mathrm{~cm}^{-3}\right)^{66}$. The reasonable operation of perovskite devices even with moderate defect densities suggests that their electronic behavior is remarkably defect-tolerant compared to other semiconductors. This could be partly because the charged carrier, once trapped, fills the trap for a very long time $(\sim 10-100 \mu \mathrm{s})$ before recombining with a free carrier of the opposite polarity ${ }^{16,60}$. This slow recombination of trapped carriers could arise because the traps in perovskites are, at least in part, related to ionic charged defects ${ }^{67}$, and charged trapped carriers could therefore be screened from recombination. The fact the trapmediated recombination is slow helps to rationalize the high observed open-circuit voltages in perovskite solar cells despite such moderately high defect densities ${ }^{60}$.

For $\mathrm{MAPbI}_{3}$, a large proportion of the chemical defects in the $1.6 \mathrm{eV}$ materials introduce trap states that are predominantly within the conduction (CB) and valence bands (VB) and therefore many defects are benign ${ }^{67,68}$. For the larger bandgap perovskites, these defect states would shift into the sub-gap region and likely have more impact on trapping charge carriers ${ }^{18,69}$, which could explain the more substantial non-radiative decay in those compositions ${ }^{12,13}$, particularly towards the blue bandgaps ${ }^{18,37,70}$. For certain mixed halide fractions in $\operatorname{MAPb}\left(\mathrm{I}_{1-\mathrm{x}} \mathrm{Br}_{\mathrm{x}}\right)_{3}$, there are additional parasitic losses introduced from photo-induced segregation into lower-bandgap iodide-rich trap states that quench excitations ${ }^{71}$. These wide bandgap absorbers/emitters are particularly important for colored LEDs and perovskite-perovskite tandems $\mathrm{s}^{32}$ and so will become a topic of intense focus in the near future. The lower-dimension layered and nanocrystal perovskite analogues are also generating enormous interest, and the defect chemistry and charge carrier recombination pathways in these materials, which have sizeable exciton binding energies, will continue to be important ongoing topics ${ }^{14,72-74}$. 

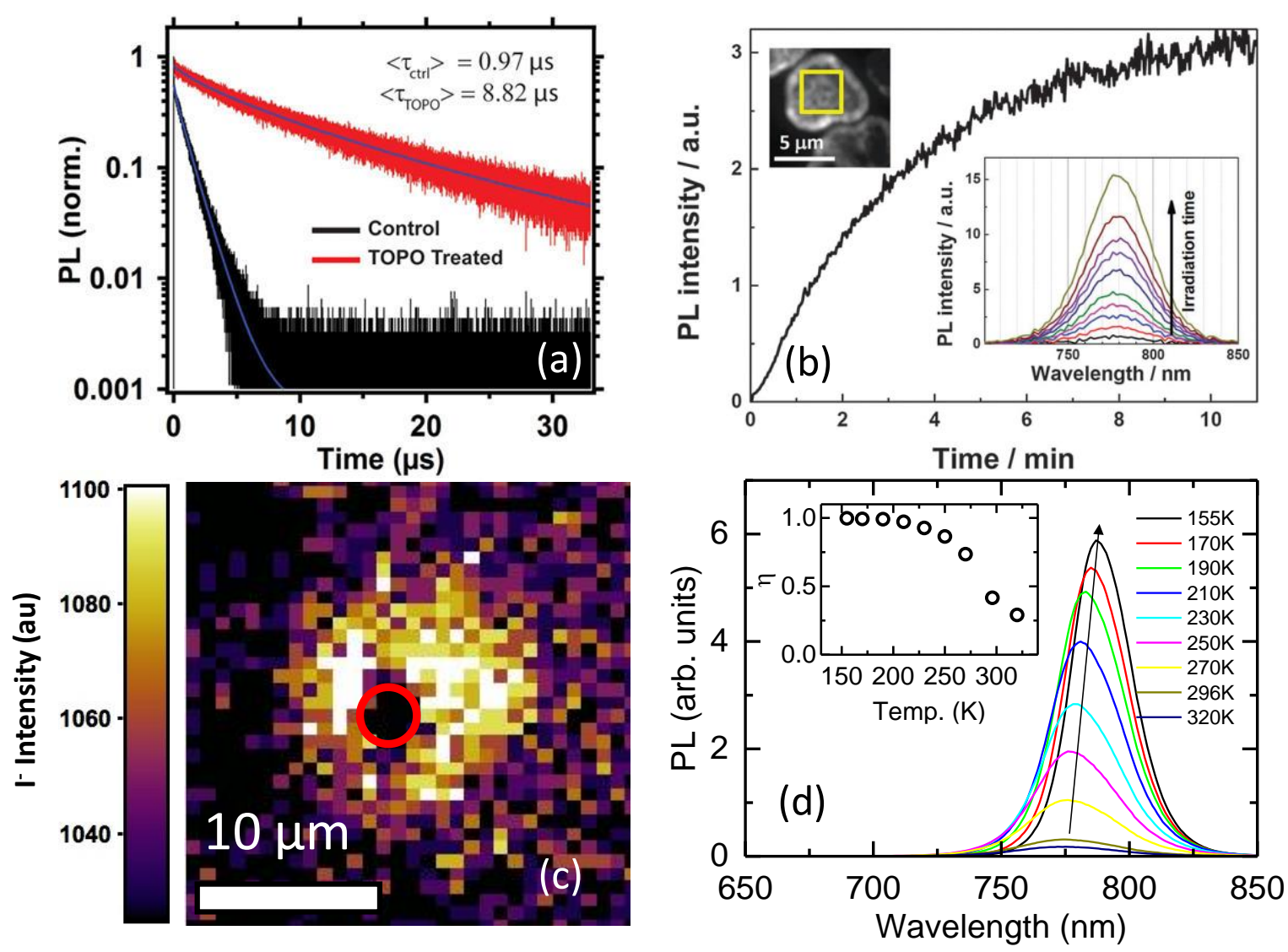

Figure 3. PL enhancements achieved through (a) surface passivation, (b) light illumination with (c) related ionic motion, and (d) lowering temperature. (a) Time-resolved PL decay traces of control (black) and trioctylphosphine-oxide (TOPO, red)-treated $\mathrm{MAPbI}_{3}$ films on glass excited with pulsed excitation $\left(470 \mathrm{~nm}, 30 \mathrm{kHz}\right.$ repetition rate, $50 \mathrm{~nJ} / \mathrm{cm}^{2}$ per pulse). Reprinted from Ref. 75. (b) PL intensity of an isolated $\mathrm{MAPbI}_{3}$ crystallite during light irradiation with a CW 514-nm laser $\left(0.3 \mathrm{~W} / \mathrm{cm}^{2}\right)$, with the PL micrograph and illuminated region shown in the inset. The PL spectra are shown in the other inset indicating no spectral change during illumination. Reprinted from Ref. ${ }^{76}$ with permission from the PCCP Owner Societies. (c) Time-of-flight secondary ion mass spectrometry (ToF-SIMS) image of the iodide $\left(\mathrm{I}^{-}\right)$distribution summed through the film depth on a region light-soaked with a $470-\mathrm{nm}$ laser with a total photon dose of $1.2 \mathrm{~kJ} / \mathrm{cm}^{2}$. The red circle denotes the FWHM of the light-soaking laser, showing that iodide is depleted in the 
illuminated region and the adjacent regions are enriched in iodide. Adapted with permission from Nature Publishing Group ${ }^{39}$. (d) External PL spectra as a function of temperature with 507-nm excitation $\left(\sim 150 \mathrm{~mW} / \mathrm{cm}^{2}\right)$. Inset: Internal PLQE $(\eta)$ measurements calculated from external measurements using the approach of Richter et $\mathrm{al}^{38}$. Adapted with permission from the American Physical Society ${ }^{16}$.

There is a growing number of reports in the literature in which these non-radiative processes are reduced, which hint at routes towards defect-free materials. These include:

i) Chemical surface treatments are a common passivation approach in semiconductor systems. Noel et al. showed that (electron-donating) Lewis base molecules such as pyridine and thiophene could increase the PL quantum efficiency and PL lifetime by reducing the defect density by an order of magnitude ${ }^{44,}{ }^{77}$. Eperon et al. ${ }^{78}$ and You et al. ${ }^{79}$ reported that exposure of the films to moisture during preparation or through a post-treatment was crucial in obtaining moderate emission and device performance, suggesting that moisture could also passivate the films. These results are consistent with recent reports on perovskite single crystals in which the surface photoluminescence properties could be reversibly modulated by the physisorption of oxygen and water molecules $^{80,81}$. Recently, deQuilettes et al. demonstrated PL lifetimes increasing from $\sim 1 \mu \mathrm{s}$ to $\sim 8 \mu$ s through treatment of the thin films with tri- $n$-octylphosphine oxide (TOPO) ligands ${ }^{75}$ (Figure 3a). They find that the external PLQE of the treated films reach $\sim 40 \%$, which converts to an internal PLQE of $\sim 80 \%$ assuming similar outcoupling properties of the film to that measured in Fig. 2a. They show that the ligands primarily bind to the film surface, suggesting that a large density of the defects reside at the surfaces. They also find that the ligands are acting as electron donors, potentially giving indirect evidence that the passivation proceeds through binding to 
uncoordinated cationic sites (e.g. lead). The effective use of surface treatments is consistent with the very high PL quantum yields of perovskite nanocrystals (approaching $100 \%$ internal yields) ${ }^{82-}$ ${ }^{84}$, with surfaces well passivated by coordinating ligands.

ii) Light-soaking. Recently, we and others demonstrated that light-soaking films could achieve similar but reversible reductions in trap density and enhancements in emission properties (Figure $3 b)^{16,39,76,85}$. We found that these enhancements correlated with a photo-induced migration of iodide species away from the illuminated region (Figure 3c), suggesting that the traps are intimately related to iodide species. There is an open question about whether the traps are iodide species themselves (e.g. interstitials ${ }^{86}$ ), and the act of clearing these from the illuminated region removes the traps, or whether they are related to the corresponding iodide vacancies, where moving excess surface iodide through the film leads to bulk trap annihilation.

There is also not yet consensus in the field as to whether light soaking always leads to enhancements in the emission properties or whether the process can also be detrimental to performance. For example, Gottesman et al. ${ }^{87}$ and Nie et al. ${ }^{88}$ found that light exposure actually decreases the PL of the film, which recovers in the dark. The conflicting results in the literature can be partially disentangled by considering that the light soaking effects depend strongly on the i) photon dose (i.e. illumination time and intensity) and ii) atmosphere of the sample during preparation, storage and measurement (i.e. atmospheric history). At very high photon doses, the PL enhancements diminish and there is a (reversible) drop in the emission level ${ }^{39,88}$. Tian et al. $^{76}$ and Galisteo-Lopez et al ${ }^{89}$ reported that the photo-brightening effects were boosted in the presence of oxygen. Understanding the mechanism by which light reduces the defect density through photoinduced ion migration, and the influence of atmospheric molecules such as oxygen, will yield crucial insight into the origins of the non-radiative decay. 
iii) Compositional control. The correlations between enhanced PL and reduction in iodine content (cf. Figure 3c) suggests that the emission properties are sensitive to local stoichiometry. It is not clear whether films with stoichiometric compositions are preferable or whether halide-deficiencies in fact lead to better emission properties. Recent work suggests that under-stoichiometric compositions (i.e. a deficiency of $\mathrm{PbI}_{2}$ in the precursor solution) lead to enhanced PL properties and open-circuit voltages in full devices ${ }^{45}$. The impact on the full device is debated as excess $\mathrm{PbI}_{2}$ appears to be beneficial to other device parameters, presumably because of resulting changes in work function, film formation etc. The self-assembly of perovskite grains from precursor salts makes it difficult to distinguish how changes in precursor ingredients directly impact the final film. For example, deQuilettes et al. showed that the local PL properties in perovskite films processed using $\mathrm{PbCl}_{2}$ precursors (denoted $\mathrm{MAPbI}_{3-\mathrm{x}} \mathrm{Cl}_{\mathrm{x}}$, where $\mathrm{x}$ is very small in the final films) positively correlate with local chloride-rich regions, but it is unclear whether the presence of chloride itself is essential or whether it is residual chloride which assisted the growth of a high quality grain. The presence of $\mathrm{Rb}$ in the recent report of highly electro-luminescent perovskite devices leaves the same open question ${ }^{34}$. The distinction will likely depend sensitively on the perovskite processing route, as each solution-processed route requires the complicated simultaneous crystallisation seeding, crystal formation and evaporation of solvent and/or any spectator species ${ }^{90}$, all of which will be influenced by the stoichiometries of the precursors. It will be important to distinguish which species play active roles in the optoelectronic properties of the final films in order to controllably design optimal compositions. The deposition of high-quality perovskite films from inks containing pre-formed nanocrystals represents another controllable way forward that avoids some of these complications $^{83,84}$. 
iv) Low temperature. In Figure 3d, the PL of a thin film of $\mathrm{MAPbI}_{3}$ is shown as a function of temperature, with the internal PLQE $\eta$ (calculated from the measured external PLQE) shown in the inset ${ }^{16,91}$. At $\sim 150 \mathrm{~K}$, the internal PLQE approaches $100 \%$, suggesting that the defects related to non-radiative decay are mitigated. The general trend of the large increase in PL with decreasing temperature is also seen in single crystal samples ${ }^{92}$. One possible explanation is that the concentration of intrinsic defects could be exponentially sensitive to temperature following a Boltzmann distribution, thus leading to the decrease in trap densities at lower temperature. Alternatively, there could be a dark carrier filling of a band of sub-gap trap states that is filled at around $\sim 150 \mathrm{~K}$. This filling is consistent with the profile of trap states presented by Baumann et al. ${ }^{93}$, who reported that the sub-gap trap states are predominantly filled at $\sim 150 \mathrm{~K}$. The success of passivation approaches indicates that it might be possible to suppress or fill the sub-gap states in a similar way but at room temperature.

Ionic migration is an unwanted phenomenon in perovskite materials which leads to inferior performance and instabilities in devices. Ion motion has been attributed to be the cause of hysteresis in operating solar cells ${ }^{94}$ and LEDs ${ }^{95}$ as well as other transient phenomena (on a time scale of seconds to minutes) under light or electrical bias ${ }^{96-98}$. In mixed bromide/iodide perovskites, light-soaking leads to an unwanted photo-induced halide segregation within the perovskite into iodide-rich domains with a lower bandgap ${ }^{71}$. This effect is somewhat mitigated in a narrow bandgap range via substitution of MA for FA and/or $\mathrm{Cs}^{35,99}$ though for most configurations and even for these 'photo-stable' complexes the consensus is that ion migration still occurs. The interesting correlation between the slow transient rises in luminescence under light (Figure 3b) and the light-induced ionic migration (Figure $3 \mathrm{c})^{39}$ suggests the mechanism for ionic migration is intimately related to the non-radiative decay pathways; indeed, hysteresis in operating solar cells 
is best modelled in the presence of both ion migration and traps ${ }^{100}$. This could be because the traps associated with non-radiative decay are related to ionic vacancies or interstitials ${ }^{101}$, which are themselves mobile, particularly under light or fields ${ }^{39,102}$. This connection leads to the tantalising prospect that eliminating the non-radiative pathways could also arrest ion migration.
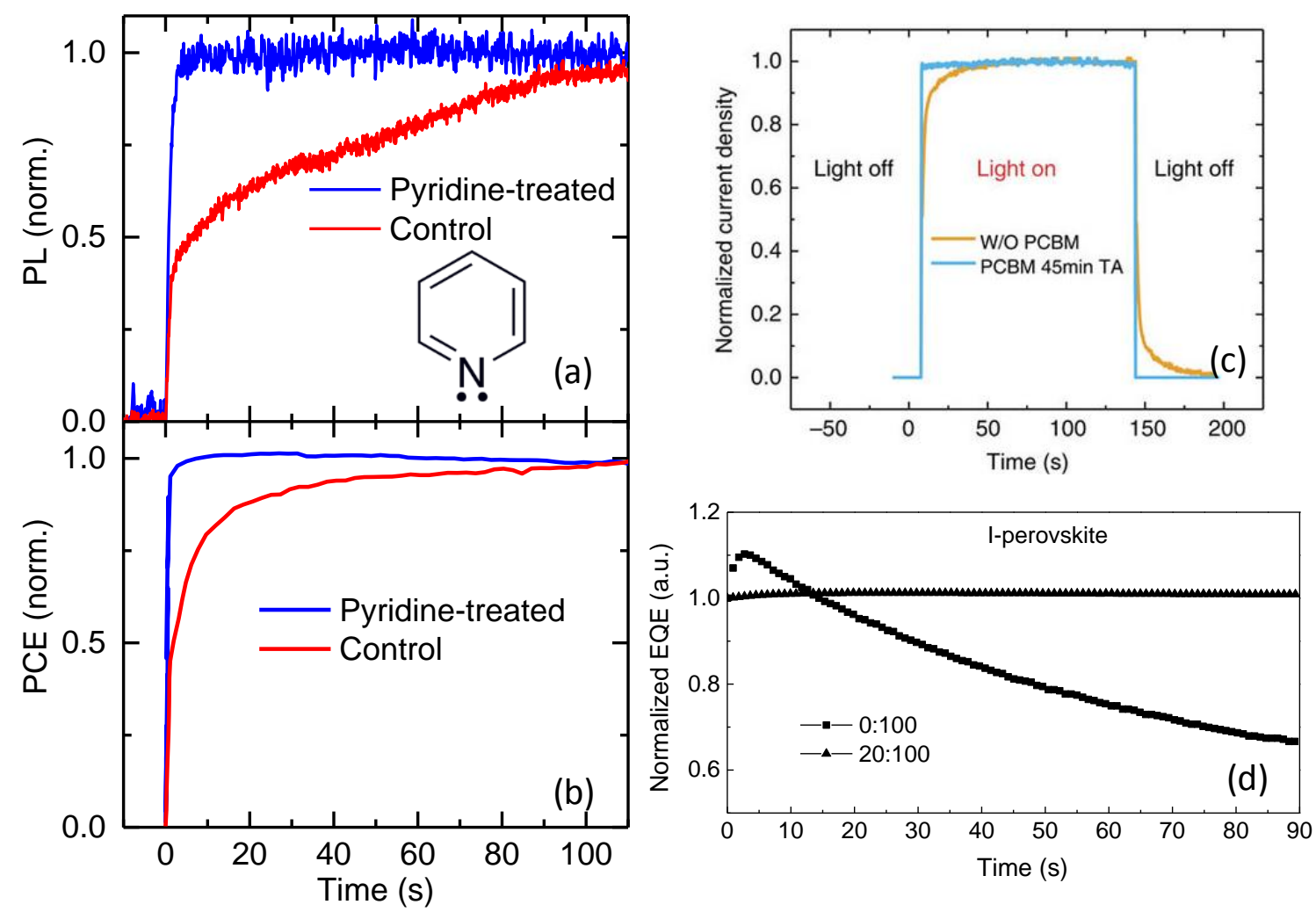

Figure 4. Arresting transient behavior through passivation. (a) PL rises over time under illumination with a $532-\mathrm{nm} \mathrm{CW}$ laser $\left(\sim 60 \mathrm{~mW} / \mathrm{cm}^{2}\right.$, equivalent photo-excited density to 1 -sun illumination) for untreated control $\mathrm{MAPbI}_{3}$ and pyridine-vapor-treated $\mathrm{MAPbI}_{3}$ thin films in a nitrogen glove box. $\mathrm{MAPbI}_{3}$ films were prepared using the solvent dripping method ${ }^{103}$. (b) Normalized stabilized maximum power output of a control device and pyridine-treated $\mathrm{MAPbI}_{3}$ planar heterojunction n-i-p device measured under solar illumination conditions. Data first presented in Ref. ${ }^{77}$. (c) Photocurrent rising process when turning on and turning off the incident 
light for perovskites devices without PCBM layer (yellow) and with PCBM layer after 45 min thermal annealing (blue). Reproduced with permission from Nature Publishing Group ${ }^{104}$. (d) Steady-state EQE measurements over time of perovskite LEDs with BAI:MAPbI 3 molar ratios of 0:100 and 20:100 at a constant voltage of 5.0 V. Reproduced with permission from Nature Publishing Group ${ }^{7}$.

To demonstrate this concept, the PL rise over time under illumination for an untreated $\mathrm{MAPbI}_{3}$ and a film that has been passivated with pyridine vapor (following the method of deQuilettes et $\mathrm{al}^{44}$ ) is shown in Figure 4a. The slow transient rise in emission, which is associated with ionic migration $^{39}$, is almost entirely eliminated in the passivated sample, which has a near-instant rise to the maximum and stable emission output. We see a very similar behavior when monitoring the maximum power output of a full planar heterojunction device (Figure 4b), where the passivated system very quickly reaches its stabilized maximum power output ${ }^{77}$. Similarly, fullerene-based electron acceptors such as phenyl- $\mathrm{C}_{61}$-butyric acid methyl ester (PCBM) have been shown to passivate perovskite surfaces ${ }^{104}, 105$, potentially by infiltrating between grain boundaries, and devices using PCBM-based electron transporting layers exhibit reduced hysteresis ${ }^{6}$ and a rapid rise to stabilized device current output ${ }^{104,105}$ (Figure 4c). Recently, Xiao et al. used large-group ligands such as $n$-butylammonium (BA) to constrain the growth of three-dimensional $\mathrm{MAPbI}_{3}$ and $\mathrm{MAPbBr}_{3}$ perovskite grains to small crystallites which have well-passivated surfaces and are efficient emitters $^{7}$. The external quantum efficiency (EQE) of the electroluminescence of LED devices constructed from these materials show a stabilized output, as compared to the transient rises and decays of the output from a device comprised of the materials without the growth constraint and passivating BA ligands (Figure 4d). These reports are consistent with slow transient 
effects associated with ion migration being suppressed in perovskites with lower trap densities. Future work to combat both ionic motion and non-radiative decay should target the elimination of defects that could be common origins to both phenomena.

In summary, metal halide perovskites have enormous potential for optoelectronic applications including high-performance solar cells and bright, highly-emissive LEDs. However, their performance is currently limited by poorly-understood non-radiative recombination pathways under device operating charge densities, which are manifested on the microscale as bright and dark grains in emission. The removal of these non-radiative channels through treatments including chemical surface passivation, light-soaking and lowering temperature, cumulatively help us to build up a picture of the origins of these losses and rational ways to eliminate them. The intimate connection between non-radiative losses and ionic motion suggests that they share common origins and therefore may share common solutions.

However, there still remain a number of open questions that must be resolved for us to fully understand these phenomena and, more generally, the recombination behaviour in such materials that show remarkable defect tolerance. Recent work has revealed that local chemical properties ${ }^{39}$ and even local structural properties ${ }^{91}$ can substantially influence the recombination behaviour, suggesting we may need to target growth of specific grain orientations with specific local chemistry (e.g. with deficiencies or excess of halides) for optimal performance. The desired optimal compositions will be further influenced by how a contact then interfaces with these grains in a full device ${ }^{106}$. These interfaces could potentially introduce new defects as well as new requirements on the grain properties to optimize both charge collection at short-circuit and radiative recombination in the perovskite at open-circuit. Their remarkable defect tolerance may also, in turn, be related to their curiously slow recombination rates. Recent works have proposed 
that these observations could be due to an indirect-direct character of the bandgap ${ }^{107-109}$ or polaronic screening effects ${ }^{110,111}$, and the relationship between these phenomena and non-radiative decay channels ${ }^{112}$ will be a topic of hot interest moving forward. The origin of the non-radiative bimolecular recombination constant will also be of broad interest to the community as it may hold the key to eliminating the final non-radiative recombination losses ${ }^{38}$. Finding answers to many of these open questions will lead to a fundamental understanding of the non-radiative losses and ionic migration, leading to rational pathways to remove or exploit these phenomena and, ultimately, yielding devices approaching their theoretical limits.

\section{Quotes to highlight in paper}

“A good analogy for voltage losses from non-radiative decay is a 'leaky' dam, where parasitic leak (loss) pathways will impair our ability to maintain the water level (voltage) at its highest possible level."

"The reasonable operation of perovskite devices even with moderate defect densities suggests that their electronic behavior is remarkably defect-tolerant compared to other semiconductors."

"There is a growing number of reports in the literature in which these non-radiative processes are reduced, which hint at routes towards defect-free materials."

"The intimate connection between non-radiative losses and ionic motion suggests that they share common origins and therefore may share common solutions."

\section{AUTHOR INFORMATION}

sds65@cam.ac.uk

http://www.stranks.oe.phy.cam.ac.uk 


\section{ACKNOWLEDGMENT}

This work has received funding from the People Programme (Marie Curie Actions) of the

European Union's Seventh Framework Programme (FP7/2007-2013) under REA grant agreement

number PIOF-GA-2013-622630. I thank Matthew T. Klug for preparing the Table of Contents

artwork and Dane deQuilettes and Barry P. Rand for fruitful discussions.

\section{REFERENCES}

(1) Saliba, M.; Matsui, T.; Seo, J. Y.; Domanski, K.; Correa-Baena, J. P.; Nazeeruddin, M. K.; Zakeeruddin, S. M.; Tress, W.; Abate, A.; Hagfeldt, A., et al. Cesium-Containing Triple Cation Perovskite Solar Cells: Improved Stability, Reproducibility and High Efficiency. Energy Environ. Sci. 2016, 9, 1989-1997.

(2) Eperon, G. E.; Stranks, S. D.; Menelaou, C.; Johnston, M. B.; Herz, L. M.; Snaith, H. J. Formamidinium Lead Trihalide: A Broadly Tunable Perovskite for Efficient Planar Heterojunction Solar Cells. Energy Environ. Sci. 2014, 7, 982-988.

(3) De Wolf, S.; Holovsky, J.; Moon, S.-J.; Löper, P.; Niesen, B.; Ledinsky, M.; Haug, F.-J.; Yum, J.-H.; Ballif, C. Organometallic Halide Perovskites: Sharp Optical Absorption Edge and Its Relation to Photovoltaic Performance. J. Phys. Chem. Lett. 2014, 5, 1035-1039.

(4) Stranks, S. D.; Eperon, G. E.; Grancini, G.; Menelaou, C.; Alcocer, M. J.; Leijtens, T.; Herz, L. M.; Petrozza, A.; Snaith, H. J. Electron-Hole Diffusion Lengths Exceeding 1 Micrometer in an Organometal Trihalide Perovskite Absorber. Science 2013, 342, 341-4.

(5) Shin, S. S.; Yeom, E. J.; Yang, W. S.; Hur, S.; Kim, M. G.; Im, J.; Seo, J.; Noh, J. H.; Seok, S. I. Colloidally Prepared La-Doped Basno3; Electrodes for Efficient, Photostable Perovskite Solar Cells. Science 2017, 356, 167.

(6) Stranks, S. D.; Snaith, H. J. Metal-Halide Perovskites for Photovoltaic and LightEmitting Devices. Nat. Nanotechnol. 2015, 10, 391-402.

(7) Xiao, Z.; Kerner, R. A.; Zhao, L.; Tran, N. L.; Lee, K. M.; Koh, T.-W.; Scholes, G. D.; Rand, B. P. Efficient Perovskite Light-Emitting Diodes Featuring Nanometre-Sized Crystallites. Nature Photonics 2017, 11, 108-115.

(8) Akkerman, Q. A.; D’Innocenzo, V.; Accornero, S.; Scarpellini, A.; Petrozza, A.; Prato, M.; Manna, L. Tuning the Optical Properties of Cesium Lead Halide Perovskite Nanocrystals by Anion Exchange Reactions. J. Am. Chem. Soc. 2015, 137, 10276-10281.

(9) Pathak, S.; Sakai, N.; Wisnivesky Rocca Rivarola, F.; Stranks, S. D.; Liu, J.; Eperon, G. E.; Ducati, C.; Wojciechowski, K.; Griffiths, J. T.; Haghighirad, A. A., et al. Perovskite Crystals for Tunable White Light Emission. Chem. Mater. 2015, 27, 8066-8075.

(10) Nedelcu, G.; Protesescu, L.; Yakunin, S.; Bodnarchuk, M. I.; Grotevent, M. J.; Kovalenko, M. V. Fast Anion-Exchange in Highly Luminescent Nanocrystals of Cesium Lead Halide Perovskites (Cspbx3, X = Cl, Br, I). Nano Lett. 2015, 15, 5635-40. 
(11) Weidman, M. C.; Seitz, M.; Stranks, S. D.; Tisdale, W. A. Highly Tunable Colloidal Perovskite Nanoplatelets through Variable Cation, Metal, and Halide Composition. ACS Nano 2016, 10, 7830-9.

(12) Sutherland, B. R.; Sargent, E. H. Perovskite Photonic Sources. Nat. Photon. 2016, 10, 295-302.

(13) Wang, N.; Cheng, L.; Ge, R.; Zhang, S.; Miao, Y.; Zou, W.; Yi, C.; Sun, Y.; Cao, Y.; Yang, R., et al. Perovskite Light-Emitting Diodes Based on Solution-Processed Self-Organized Multiple Quantum Wells. Nat. Photon. 2016, 10, 699-704.

(14) Yuan, M.; Quan, L. N.; Comin, R.; Walters, G.; Sabatini, R.; Voznyy, O.; Hoogland, S.; Zhao, Y.; Beauregard, E. M.; Kanjanaboos, P., et al. Perovskite Energy Funnels for Efficient Light-Emitting Diodes. Nat. Nanotechnol. 2016, 11, 872-877.

(15) Deschler, F.; Price, M.; Pathak, S.; Klintberg, L. E.; Jarausch, D.-D.; Higler, R.; Hüttner, S.; Leijtens, T.; Stranks, S. D.; Snaith, H. J., et al. High Photoluminescence Efficiency and Optically Pumped Lasing in Solution-Processed Mixed Halide Perovskite Semiconductors. J. Phys. Chem. Lett. 2014, 5, 1421-1426.

(16) Stranks, S. D.; Burlakov, V. M.; Leijtens, T.; Ball, J. M.; Goriely, A.; Snaith, H. J. Recombination Kinetics in Organic-Inorganic Perovskites: Excitons, Free Charge, and Subgap States. Phys. Rev. Appl. 2014, 2, 034007.

(17) Sutter-Fella, C. M.; Li, Y.; Amani, M.; Ager, J. W.; Toma, F. M.; Yablonovitch, E.; Sharp, I. D.; Javey, A. High Photoluminescence Quantum Yield in Band Gap Tunable Bromide Containing Mixed Halide Perovskites. Nano Lett. 2016, 16, 800-806.

(18) Comin, R.; Walters, G.; Thibau, E. S.; Voznyy, O.; Lu, Z.-H.; Sargent, E. H. Structural, Optical, and Electronic Studies of Wide-Bandgap Lead Halide Perovskites. J. Mater. Chem. C 2015, 3, 8839-8843.

(19) Tress, W.; Marinova, N.; Inganäs, O.; Nazeeruddin, M. K.; Zakeeruddin, S. M.; Graetzel, M. Predicting the Open-Circuit Voltage of Ch3nh3pbi3 Perovskite Solar Cells Using Electroluminescence and Photovoltaic Quantum Efficiency Spectra: The Role of Radiative and Non-Radiative Recombination. Adv. Energy Mater. 2015, 5, 1400812.

(20) Miller, O. D.; Yablonovitch, E.; Kurtz, S. R. Strong Internal and External Luminescence as Solar Cells Approach the Shockley-Queisser Limit. IEEE J. Photovolt. 2012, 2, 303-311.

(21) Rau, U. Reciprocity Relation between Photovoltaic Quantum Efficiency and Electroluminescent Emission of Solar Cells. Phys. Rev. B 2007, 76, 085303.

(22) Ross, R. T. Some Thermodynamics of Photochemical Systems. J. Chem. Phys. 1967, 46, 4590-4593.

(23) Ball, J. M.; Stranks, S. D.; Hörantner, M. T.; Hüttner, S.; Zhang, W.; Crossland, E. J. W.; Ramirez, I.; Riede, M.; Johnston, M. B.; Friend, R. H., et al. Optical Properties and Limiting Photocurrent of Thin-Film Perovskite Solar Cells. Energy Environ. Sci. 2015, 8, 602-609.

(24) Pazos-Outón, L. M.; Szumilo, M.; Lamboll, R.; Richter, J. M.; Crespo-Quesada, M.; Abdi-Jalebi, M.; Beeson, H. J.; Vrućinić, M.; Alsari, M.; Snaith, H. J., et al. Photon Recycling in Lead Iodide Perovskite Solar Cells. Science 2016, 351, 1430-1433.

(25) Ganapati, V.; Steiner, M. A.; Yablonovitch, E. The Voltage Boost Enabled by Luminescence Extraction in Solar Cells. IEEE J. Photovolt. 2016, 6, 801-809.

(26) Green, M. A. Radiative Efficiency of State-of-the-Art Photovoltaic Cells. Progress in Photovoltaics: Research and Applications 2012, 20, 472-476.

(27) Green, M. A.; Bremner, S. P. Energy Conversion Approaches and Materials for HighEfficiency Photovoltaics. Nat. Mater. 2017, 16, 23-34. 
(28) Schnitzer, I.; Yablonovitch, E.; Caneau, C.; Gmitter, T. J. Ultrahigh Spontaneous Emission Quantum Efficiency, 99.7\% Internally and 72\% Externally, from Algaas/Gaas/Algaas Double Heterostructures. Appl. Phys. Lett. 1993, 62, 131-133.

(29) Yao, J.; Kirchartz, T.; Vezie, M. S.; Faist, M. A.; Gong, W.; He, Z.; Wu, H.; Troughton, J.; Watson, T.; Bryant, D., et al. Quantifying Losses in Open-Circuit Voltage in SolutionProcessable Solar Cells. Phys. Rev. Appl. 2015, 4, 014020.

(30) Green, M. A.; Emery, K.; Hishikawa, Y.; Warta, W.; Dunlop, E. D.; Levi, D. H.; HoBaillie, A. W. Y. Solar Cell Efficiency Tables (Version 49). Progress in Photovoltaics: Research and Applications 2017, 25, 3-13.

(31) Burst, J. M.; Duenow, J. N.; Albin, D. S.; Colegrove, E.; Reese, M. O.; Aguiar, J. A.; Jiang, C. S.; Patel, M. K.; Al-Jassim, M. M.; Kuciauskas, D., et al. Cdte Solar Cells with OpenCircuit Voltage Breaking the $1 \mathrm{~V}$ Barrier. Nat. Energy 2016, 1, 16015.

(32) Eperon, G. E.; Leijtens, T.; Bush, K. A.; Prasanna, R.; Green, T.; Wang, J. T.; McMeekin, D. P.; Volonakis, G.; Milot, R. L.; May, R., et al. Perovskite-Perovskite Tandem Photovoltaics with Optimized Band Gaps. Science 2016, 354, 861-865.

(33) Momblona, C.; Gil-Escrig, L.; Bandiello, E.; Hutter, E. M.; Sessolo, M.; Lederer, K.; Blochwitz-Nimoth, J.; Bolink, H. J. Efficient Vacuum Deposited P-I-N and N-I-P Perovskite Solar Cells Employing Doped Charge Transport Layers. Energy Environ. Sci. 2016, 9, 34563463.

(34) Saliba, M.; Matsui, T.; Domanski, K.; Seo, J. Y.; Ummadisingu, A.; Zakeeruddin, S. M.; Correa-Baena, J. P.; Tress, W. R.; Abate, A.; Hagfeldt, A., et al. Incorporation of Rubidium Cations into Perovskite Solar Cells Improves Photovoltaic Performance. Science 2016, 354, 206209.

(35) McMeekin, D. P.; Sadoughi, G.; Rehman, W.; Eperon, G. E.; Saliba, M.; Hörantner, M. T.; Haghighirad, A.; Sakai, N.; Korte, L.; Rech, B., et al. A Mixed-Cation Lead Mixed-Halide Perovskite Absorber for Tandem Solar Cells. Science 2016, 351, 151-155.

(36) Tvingstedt, K.; Malinkiewicz, O.; Baumann, A.; Deibel, C.; Snaith, H. J.; Dyakonov, V.; Bolink, H. J. Radiative Efficiency of Lead Iodide Based Perovskite Solar Cells. Sci. Rep. 2014, 4, 6071 .

(37) Paulke, A.; Stranks, S. D.; Kniepert, J.; Kurpiers, J.; Wolff, C. M.; Schön, N.; Snaith, H. J.; Brenner, T. J. K.; Neher, D. Charge Carrier Recombination Dynamics in Perovskite and Polymer Solar Cells. Appl. Phys. Lett. 2016, 108, 113505.

(38) Richter, J. M.; Abdi-Jalebi, M.; Sadhanala, A.; Tabachnyk, M.; Rivett, J. P. H.; PazosOutón, L. M.; Gödel, K. C.; Price, M.; Deschler, F.; Friend, R. H. Enhancing Photoluminescence Yields in Lead Halide Perovskites by Photon Recycling and Light out-Coupling. Nat. Commun. 2016, 7, 13941.

(39) deQuilettes, D. W.; Zhang, W.; Burlakov, V. M.; Graham, D. J.; Leijtens, T.; Osherov, A.; Bulovic, V.; Snaith, H. J.; Ginger, D. S.; Stranks, S. D. Photo-Induced Halide Redistribution in Organic-Inorganic Perovskite Films. Nat. Commun. 2016, 7, 11683.

(40) Wehrenfennig, C.; Eperon, G. E.; Johnston, M. B.; Snaith, H. J.; Herz, L. M. High Charge Carrier Mobilities and Lifetimes in Organolead Trihalide Perovskites. Adv. Mater. 2014, 26, 1584-1589.

(41) Galkowski, K.; Mitioglu, A.; Miyata, A.; Plochocka, P.; Portugall, O.; Eperon, G. E.; Wang, J. T.-W.; Stergiopoulos, T.; Stranks, S. D.; Snaith, H. J., et al. Determination of the Exciton Binding Energy and Effective Masses for Methylammonium and Formamidinium Lead Tri-Halide Perovskite Semiconductors. Energy Environ. Sci. 2016, 9, 962-970. 
(42) Miyata, A.; Mitioglu, A.; Plochocka, P.; Portugall, O.; Wang, J. T.-W.; Stranks, S. D.; Snaith, H. J.; Nicholas, R. J. Direct Measurement of the Exciton Binding Energy and Effective Masses for Charge Carriers in Organic-Inorganic Tri-Halide Perovskites. Nat. Phys. 2015, 11, 582-587.

(43) Hutter, E. M.; Eperon, G. E.; Stranks, S. D.; Savenije, T. J. Charge Carriers in Planar and Meso-Structured Organic-Inorganic Perovskites: Mobilities, Lifetimes, and Concentrations of Trap States. J. Phys. Chem. Lett. 2015, 6, 3082-90.

(44) deQuilettes, D. W.; Vorpahl, S. M.; Stranks, S. D.; Nagaoka, H.; Eperon, G. E.; Ziffer, M. E.; Snaith, H. J.; Ginger, D. S. Impact of Microstructure on Local Carrier Lifetime in Perovskite Solar Cells. Science 2015, 348, 683-686.

(45) Jacobsson, T. J.; Correa-Baena, J. P.; Halvani Anaraki, E.; Philippe, B.; Stranks, S. D.; Bouduban, M. E.; Tress, W.; Schenk, K.; Teuscher, J.; Moser, J. E., et al. Unreacted Pbi2 as a Double-Edged Sword for Enhancing the Performance of Perovskite Solar Cells. J. Am. Chem. Soc. 2016, 138, 10331-43.

(46) Draguta, S.; Thakur, S.; Morozov, Y. V.; Wang, Y.; Manser, J. S.; Kamat, P. V.; Kuno, M. Spatially Non-Uniform Trap State Densities in Solution-Processed Hybrid Perovskite Thin Films. J. Phys. Chem. Lett. 2016, 7, 715-721.

(47) Simpson, M. J.; Doughty, B.; Yang, B.; Xiao, K.; Ma, Y. Z. Spatial Localization of Excitons and Charge Carriers in Hybrid Perovskite Thin Films. J. Phys. Chem. Lett. 2015, 6, 3041-7.

(48) Tian, Y.; Merdasa, A.; Peter, M.; Abdellah, M.; Zheng, K.; Ponseca, C. S.; Pullerits, T.; Yartsev, A.; Sundström, V.; Scheblykin, I. G. Giant Photoluminescence Blinking of Perovskite Nanocrystals Reveals Single-Trap Control of Luminescence. Nano Lett. 2015, 15, 1603-1608. (49) Guo, Z.; Manser, J. S.; Wan, Y.; Kamat, P. V.; Huang, L. Spatial and Temporal Imaging of Long-Range Charge Transport in Perovskite Thin Films by Ultrafast Microscopy. Nat. Commun. 2015, 6, 7471.

(50) Stranks, S. D.; Petrozza, A. Revisiting Photocarrier Lifetimes in Photovoltaics. Nat. Photon. 2016, 10, 562-562.

(51) Reid, O. G.; Yang, M.; Kopidakis, N.; Zhu, K.; Rumbles, G. Grain-Size-Limited Mobility in Methylammonium Lead Iodide Perovskite Thin Films. ACS Energy Lett. 2016, 1, 561-565.

(52) Tian, W.; Cui, R.; Leng, J.; Liu, J.; Li, Y.; Zhao, C.; Zhang, J.; Deng, W.; Lian, T.; Jin, S. Limiting Perovskite Solar Cell Performance by Heterogeneous Carrier Extraction. Angew. Chem. Int. Ed. 2016, 128, 13261-13265.

(53) Yang, M.; Zeng, Y.; Li, Z.; Kim, D. H.; Jiang, C.-S.; van de Lagemaat, J.; Zhu, K. Do Grain Boundaries Dominate Non-Radiative Recombination in Ch3nh3pbi3 Perovskite Thin Films? Phys. Chem. Chem. Phys. 2017, 19, 5043-5050.

(54) Leblebici, S. Y.; Leppert, L.; Li, Y.; Reyes-Lillo, S. E.; Wickenburg, S.; Wong, E.; Lee, J.; Melli, M.; Ziegler, D.; Angell, D. K., et al. Facet-Dependent Photovoltaic Efficiency Variations in Single Grains of Hybrid Halide perovskite. Nat. Energy 2016, 1, 16093.

(55) El-Hajje, G.; Momblona, C.; Gil-Escrig, L.; Avila, J.; Guillemot, T.; Guillemoles, J.-F.; Sessolo, M.; Bolink, H. J.; Lombez, L. Quantification of Spatial Inhomogeneity in Perovskite Solar Cells by Hyperspectral Luminescence Imaging. Energy Environ. Sci. 2016, 9, 2286-2294. (56) Kutes, Y.; Zhou, Y.; Bosse, J. L.; Steffes, J.; Padture, N. P.; Huey, B. D. Mapping the Photoresponse of Ch3nh3pbi3 Hybrid Perovskite Thin Films at the Nanoscale. Nano Lett. 2016, $16,3434-41$. 
(57) Garrett, J. L.; Tennyson, E. M.; Hu, M.; Huang, J.; Munday, J. N.; Leite, M. S. RealTime Nanoscale Open-Circuit Voltage Dynamics of Perovskite Solar Cells. Nano Lett. 2017, 17 , 2554-2560.

(58) Ball, J. M.; Petrozza, A. Defects in Perovskite-Halides and Their Effects in Solar Cells. Nat. Energy 2016, 1, 16149.

(59) Wetzelaer, G. J.; Scheepers, M.; Sempere, A. M.; Momblona, C.; Avila, J.; Bolink, H. J. Trap-Assisted Non-Radiative Recombination in Organic-Inorganic Perovskite Solar Cells. Adv. Mater. 2015, 27, 1837-41.

(60) Leijtens, T.; Eperon, G. E.; Barker, A. J.; Grancini, G.; Zhang, W.; Ball, J. M.; Kandada, A. R. S.; Snaith, H. J.; Petrozza, A. Carrier Trapping and Recombination: The Role of Defect Physics in Enhancing the Open Circuit Voltage of Metal Halide Perovskite Solar Cells. Energy Environ. Sci. 2016, 9, 3472-3481.

(61) Xing, G.; Mathews, N.; Lim, S. S.; Yantara, N.; Liu, X.; Sabba, D.; Gratzel, M.; Mhaisalkar, S.; Sum, T. C. Low-Temperature Solution-Processed Wavelength-Tunable Perovskites for Lasing. Nat. Mater. 2014, 13, 476-480.

(62) Yang, Y. S.; Kim, S. H.; Lee, J.-I.; Chu, H. Y.; Do, L.-M.; Lee, H.; Oh, J.; Zyung, T. Deep-Level Defect Characteristics in Pentacene Organic Thin Films. Appl. Phys. Lett. 2002, 80, 1595-1597.

(63) Kerr, L. L.; Li, S. S.; Johnston, S. W.; Anderson, T. J.; Crisalle, O. D.; Kim, W. K.; Abushama, J.; Noufi, R. N. Investigation of Defect Properties in $\mathrm{Cu}(\mathrm{in}, \mathrm{Ga}) \mathrm{Se} 2$ Solar Cells by Deep-Level Transient Spectroscopy. Solid-State Electronics 2004, 48, 1579-1586.

(64) Shi, D.; Adinolfi, V.; Comin, R.; Yuan, M.; Alarousu, E.; Buin, A.; Chen, Y.; Hoogland, S.; Rothenberger, A.; Katsiev, K., et al. Low Trap-State Density and Long Carrier Diffusion in Organolead Trihalide Perovskite Single Crystals. Science 2015, 347, 519-522.

(65) Dong, Q.; Fang, Y.; Shao, Y.; Mulligan, P.; Qiu, J.; Cao, L.; Huang, J. Electron-Hole Diffusion Lengths $>175$ Mum in Solution-Grown Ch3nh3pbi3 Single Crystals. Science 2015, 347, 967-70.

(66) Haynes, J. R.; Hornbeck, J. A. Trapping of Minority Carriers in Silicon. Ii. N-Type Silicon. Phys. Rev. 1955, 100, 606-615.

(67) Yin, W.-J.; Shi, T.; Yan, Y. Unusual Defect Physics in Ch3nh3pbi3 Perovskite Solar Cell Absorber. Appl. Phys. Lett. 2014, 104, 063903.

(68) Wang, J.; Wang, N.; Jin, Y.; Si, J.; Tan, Z.-K.; Du, H.; Cheng, L.; Dai, X.; Bai, S.; He, H., et al. Interfacial Control toward Efficient and Low-Voltage Perovskite Light-Emitting Diodes. Adv. Mater. 2015, 27, 2311-2316.

(69) Sutter-Fella, C. M.; Miller, D. W.; Ngo, Q. P.; Roe, E. T.; Toma, F. M.; Sharp, I. D.; Lonergan, M. C.; Javey, A. Band Tailing and Deep Defect States in Ch3nh3pb(I1-Xbrx)3 Perovskites as Revealed by Sub-Bandgap Photocurrent. ACS Energy Lett. 2017, 2, 709-715.

(70) Kumar, S.; Jagielski, J.; Yakunin, S.; Rice, P.; Chiu, Y.-C.; Wang, M.; Nedelcu, G.; Kim, Y.; Lin, S.; Santos, E. J. G., et al. Efficient Blue Electroluminescence Using Quantum-Confined Two-Dimensional Perovskites. ACS Nano 2016, 10, 9720-9729.

(71) Hoke, E. T.; Slotcavage, D. J.; Dohner, E. R.; Bowring, A. R.; Karunadasa, H. I.; McGehee, M. D. Reversible Photo-Induced Trap Formation in Mixed-Halide Hybrid Perovskites for Photovoltaics. Chem. Sci. 2015, 6, 613-617.

(72) Blancon, J. C.; Tsai, H.; Nie, W.; Stoumpos, C. C.; Pedesseau, L.; Katan, C.; Kepenekian, M.; Soe, C. M. M.; Appavoo, K.; Sfeir, M. Y., et al. Extremely Efficient Internal 
Exciton Dissociation through Edge States in Layered 2d Perovskites. Science 2017, 355, 12881292.

(73) Saidaminov, M. I.; Mohammed, O. F.; Bakr, O. M. Low-Dimensional-Networked Metal Halide Perovskites: The Next Big Thing. ACS Energy Lett. 2017, 2, 889-896.

(74) Makarov, N. S.; Guo, S.; Isaienko, O.; Liu, W.; Robel, I.; Klimov, V. I. Spectral and Dynamical Properties of Single Excitons, Biexcitons, and Trions in Cesium-Lead-Halide Perovskite Quantum Dots. Nano Lett. 2016, 16, 2349-2362.

(75) deQuilettes, D. W.; Koch, S.; Burke, S.; Paranji, R. K.; Shropshire, A. J.; Ziffer, M. E.; Ginger, D. S. Photoluminescence Lifetimes Exceeding $8 \mathrm{Ms}$ and Quantum Yields Exceeding $30 \%$ in Hybrid Perovskite Thin Films by Ligand Passivation. ACS Energy Lett. 2016, 1, 438444.

(76) Tian, Y.; Peter, M.; Unger, E.; Abdellah, M.; Zheng, K.; Pullerits, T.; Yartsev, A.; Sundstrom, V.; Scheblykin, I. G. Mechanistic Insights into Perovskite Photoluminescence Enhancement: Light Curing with Oxygen Can Boost Yield Thousandfold. Phys. Chem. Chem. Phys. 2015, 17, 24978-87.

(77) Noel, N. K.; Abate, A.; Stranks, S. D.; Parrott, E. S.; Burlakov, V. M.; Goriely, A.; Snaith, H. J. Enhanced Photoluminescence and Solar Cell Performance Via Lewis Base Passivation of Organic-Inorganic Lead Halide Perovskites. ACS Nano 2014, 8, 9815-21.

(78) Eperon, G. E.; Habisreutinger, S. N.; Leijtens, T.; Bruijnaers, B. J.; van Franeker, J. J.; deQuilettes, D. W.; Pathak, S.; Sutton, R. J.; Grancini, G.; Ginger, D. S., et al. The Importance of Moisture in Hybrid Lead Halide Perovskite Thin Film Fabrication. ACS Nano 2015, 9, 9380-93.

(79) You, J.; Yang, Y.; Hong, Z.; Song, T.-B.; Meng, L.; Liu, Y.; Jiang, C.; Zhou, H.; Chang, W.-H.; Li, G., et al. Moisture Assisted Perovskite Film Growth for High Performance Solar Cells. Appl. Phys. Lett. 2014, 105, 183902.

(80) Fang, H.-H.; Adjokatse, S.; Wei, H.; Yang, J.; Blake, G. R.; Huang, J.; Even, J.; Loi, M. A. Ultrahigh Sensitivity of Methylammonium Lead Tribromide Perovskite Single Crystals to Environmental Gases. Science Adv. 2016, 2.

(81) Grancini, G.; D'Innocenzo, V.; Dohner, E. R.; Martino, N.; Srimath Kandada, A. R.; Mosconi, E.; De Angelis, F.; Karunadasa, H. I.; Hoke, E. T.; Petrozza, A. Ch3nh3pbi3 Perovskite Single Crystals: Surface Photophysics and Its Interaction with the Environment. Chemical Science 2015, 6, 7305-7310.

(82) Protesescu, L.; Yakunin, S.; Bodnarchuk, M. I.; Krieg, F.; Caputo, R.; Hendon, C. H.; Yang, R. X.; Walsh, A.; Kovalenko, M. V. Nanocrystals of Cesium Lead Halide Perovskites (Cspbx3, $\mathrm{X}=\mathrm{Cl}, \mathrm{Br}$, and I): Novel Optoelectronic Materials Showing Bright Emission with Wide Color Gamut. Nano Lett. 2015, 15, 3692-3696.

(83) Swarnkar, A.; Marshall, A. R.; Sanehira, E. M.; Chernomordik, B. D.; Moore, D. T.; Christians, J. A.; Chakrabarti, T.; Luther, J. M. Quantum Dot-Induced Phase Stabilization of ACspbi3 Perovskite for High-Efficiency Photovoltaics. Science 2016, 354, 92.

(84) Akkerman, Q. A.; Gandini, M.; Di Stasio, F.; Rastogi, P.; Palazon, F.; Bertoni, G.; Ball, J. M.; Prato, M.; Petrozza, A.; Manna, L. Strongly Emissive Perovskite Nanocrystal Inks for High-Voltage Solar Cells. Nat. Energy 2016, 2, 16194.

(85) Yamada, Y.; Endo, M.; Wakamiya, A.; Kanemitsu, Y. Spontaneous Defect Annihilation in Ch3nh3pbi3 Thin Films at Room Temperature Revealed by Time-Resolved Photoluminescence Spectroscopy. J. Phys. Chem. Lett. 2015, 6, 482-486. 
(86) Mosconi, E.; Meggiolaro, D.; Snaith, H. J.; Stranks, S. D.; De Angelis, F. Light-Induced Annihilation of Frenkel Defects in Organo-Lead Halide Perovskites. Energy Environ. Sci. 2016, 9, 3180-3187.

(87) Gottesman, R.; Gouda, L.; Kalanoor, B. S.; Haltzi, E.; Tirosh, S.; Rosh-Hodesh, E.; Tischler, Y.; Zaban, A.; Quarti, C.; Mosconi, E., et al. Photoinduced Reversible Structural Transformations in Free-Standing Ch3nh3pbi3 Perovskite Films. J. Phys. Chem. Lett. 2015, 6, 2332-2338.

(88) Nie, W.; Blancon, J.-C.; Neukirch, A. J.; Appavoo, K.; Tsai, H.; Chhowalla, M.; Alam, M. A.; Sfeir, M. Y.; Katan, C.; Even, J., et al. Light-Activated Photocurrent Degradation and Self-Healing in Perovskite Solar Cells. Nat. Commun. 2016, 7, 11574.

(89) Galisteo-López, J. F.; Anaya, M.; Calvo, M. E.; Míguez, H. Environmental Effects on the Photophysics of Organic-Inorganic Halide Perovskites. J. Phys. Chem. Lett. 2015, 6, 2200-2205. (90) Stranks, S. D.; Nayak, P. K.; Zhang, W.; Stergiopoulos, T.; Snaith, H. J. Formation of Thin Films of Organic-Inorganic Perovskites for High-Efficiency Solar Cells. Angew. Chem. Int. Ed. 2015, 54, 3240-8.

(91) Osherov, A.; Hutter, E. M.; Galkowski, K.; Brenes, R.; Maude, D. K.; Nicholas, R. J.; Plochocka, P.; Bulovic, V.; Savenije, T. J.; Stranks, S. D. The Impact of Phase Retention on the Structural and Optoelectronic Properties of Metal Halide Perovskites. Adv. Mater. 2016, 28, 10757-10763.

(92) Fang, H. H.; Raissa, R.; Abdu-Aguye, M.; Adjokatse, S.; Blake, G. R.; Even, J.; Loi, M. A. Photophysics of Organic-Inorganic Hybrid Lead Iodide Perovskite Single Crystals. Adv. Funct. Mater. 2015, 25, 2378-2385.

(93) Baumann, A.; Väth, S.; Rieder, P.; Heiber, M. C.; Tvingstedt, K.; Dyakonov, V. Identification of Trap States in Perovskite Solar Cells. J. Phys. Chem. Lett. 2015, 6, 2350-2354. (94) Snaith, H. J.; Abate, A.; Ball, J. M.; Eperon, G. E.; Leijtens, T.; Noel, N. K.; Stranks, S. D.; Wang, J. T.; Wojciechowski, K.; Zhang, W. Anomalous Hysteresis in Perovskite Solar Cells. J. Phys. Chem. Lett. 2014, 5, 1511-5.

(95) Tan, Z. K.; Moghaddam, R. S.; Lai, M. L.; Docampo, P.; Higler, R.; Deschler, F.; Price, M.; Sadhanala, A.; Pazos, L. M.; Credgington, D., et al. Bright Light-Emitting Diodes Based on Organometal Halide Perovskite. Nat. Nanotechnol. 2014, 9, 687-692.

(96) Wojciechowski, K.; Stranks, S. D.; Abate, A.; Sadoughi, G.; Sadhanala, A.; Kopidakis, N.; Rumbles, G.; Li, C. Z.; Friend, R. H.; Jen, A. K., et al. Heterojunction Modification for Highly Efficient Organic-Inorganic Perovskite Solar Cells. ACS Nano 2014, 8, 12701-9.

(97) Leijtens, T.; Hoke, E. T.; Grancini, G.; Slotcavage, D. J.; Eperon, G. E.; Ball, J. M.; De Bastiani, M.; Bowring, A. R.; Martino, N.; Wojciechowski, K., et al. Mapping Electric FieldInduced Switchable Poling and Structural Degradation in Hybrid Lead Halide Perovskite Thin Films. Adv. Energy Mater. 2015, 5.

(98) Xiao, Z.; Yuan, Y.; Shao, Y.; Wang, Q.; Dong, Q.; Bi, C.; Sharma, P.; Gruverman, A.; Huang, J. Giant Switchable Photovoltaic Effect in Organometal Trihalide Perovskite Devices. Nat. Mater. 2015, 14, 193-8.

(99) Beal, R. E.; Slotcavage, D. J.; Leijtens, T.; Bowring, A. R.; Belisle, R. A.; Nguyen, W. H.; Burkhard, G. F.; Hoke, E. T.; McGehee, M. D. Cesium Lead Halide Perovskites with Improved Stability for Tandem Solar Cells. J. Phys. Chem. Lett. 2016, 7, 746-751. (100) van Reenen, S.; Kemerink, M.; Snaith, H. J. Modeling Anomalous Hysteresis in Perovskite Solar Cells. J. Phys. Chem. Lett. 2015, 6, 3808-3814. 
(101) Eames, C.; Frost, J. M.; Barnes, P. R.; O'Regan, B. C.; Walsh, A.; Islam, M. S. Ionic Transport in Hybrid Lead Iodide Perovskite Solar Cells. Nat. Commun. 2015, 6, 7497.

(102) Yuan, Y.; Huang, J. Ion Migration in Organometal Trihalide Perovskite and Its Impact on Photovoltaic Efficiency and Stability. Acc. Chem. Res. 2016, 49, 286-293.

(103) Xiao, M.; Huang, F.; Huang, W.; Dkhissi, Y.; Zhu, Y.; Etheridge, J.; Gray-Weale, A.; Bach, U.; Cheng, Y. B.; Spiccia, L. A Fast Deposition-Crystallization Procedure for Highly Efficient Lead Iodide Perovskite Thin-Film Solar Cells. Angew. Chem. Int. Ed. 2014, 53, 9898903.

(104) Shao, Y.; Xiao, Z.; Bi, C.; Yuan, Y.; Huang, J. Origin and Elimination of Photocurrent Hysteresis by Fullerene Passivation in Ch3nh3pbi3 Planar Heterojunction Solar Cells. Nat. Commun. 2014, 5, 5784.

(105) Xu, J.; Buin, A.; Ip, A. H.; Li, W.; Voznyy, O.; Comin, R.; Yuan, M.; Jeon, S.; Ning, Z.; McDowell, J. J., et al. Perovskite-Fullerene Hybrid Materials Suppress Hysteresis in Planar Diodes. Nat. Commun. 2015, 6, 7081.

(106) Eperon, G. E.; Moerman, D.; Ginger, D. S. Anticorrelation between Local Photoluminescence and Photocurrent Suggests Variability in Contact to Active Layer in Perovskite Solar Cells. ACS Nano 2016, 10, 10258-10266.

(107) Hutter, E. M.; Gelvez-Rueda, M. C.; Osherov, A.; Bulovic, V.; Grozema, F. C.; Stranks, S. D.; Savenije, T. J. Direct-Indirect Character of the Bandgap in Methylammonium Lead Iodide Perovskite. Nat. Mater. 2017, 16, 115-120.

(108) Wang, T.; Daiber, B.; Frost, J. M.; Mann, S. A.; Garnett, E. C.; Walsh, A.; Ehrler, B. Indirect to Direct Bandgap Transition in Methylammonium Lead Halide Perovskite. Energy Environ. Sci. 2017, 10, 509-515.

(109) Azarhoosh, P.; McKechnie, S.; Frost, J. M.; Walsh, A.; van Schilfgaarde, M. Research Update: Relativistic Origin of Slow Electron-Hole Recombination in Hybrid Halide Perovskite Solar Cells. APL Mater. 2016, 4, 091501.

(110) Zhu, X. Y.; Podzorov, V. Charge Carriers in Hybrid Organic-Inorganic Lead Halide Perovskites Might Be Protected as Large Polarons. J. Phys. Chem. Lett. 2015, 6, 4758-4761. (111) Chen, Y.; Yi, H. T.; Wu, X.; Haroldson, R.; Gartstein, Y. N.; Rodionov, Y. I.; Tikhonov, K. S.; Zakhidov, A.; Zhu, X. Y.; Podzorov, V. Extended Carrier Lifetimes and Diffusion in Hybrid Perovskites Revealed by Hall Effect and Photoconductivity Measurements. Nat.

Commun. 2016, 7, 12253.

(112) Kirchartz, T.; Rau, U. Decreasing Radiative Recombination Coefficients Via an Indirect Band Gap in Lead Halide Perovskites. J. Phys. Chem. Lett. 2017, 8, 1265-1271. 